\title{
International Chamber of Commerce Rules for Trade Terms - The Terminological Approach
}

\author{
Submitted 18/12/20, $1^{\text {st }}$ revision 17/01/21, $2^{\text {nd }}$ revision 20/02/21, accepted 20/03/21
}

Vladár Zsuzsa ${ }^{1}$, Constantinovits Milán², Vasa László ${ }^{3}$

\begin{abstract}
:
Purpose: The rules of International Commercial Terms (Incoterms) define the important element of the international sales contract, the so-called parity. The parity means the place, where the cost and risks are handed over from the seller to the buyer. In this paper, we would like to answer to following questions: What are the principles of the terminological system of Incoterms editions following each other? What is the difference between the logic of the creators of terminology and its users? How does change the relationship of users and International Chamber of Commerce (ICC) in the mirror of terminological changes?

Approach/Methodology/Design: We demonstrate and analyze the modifications of Incoterms rules updated in the last 40 years focusing on the development of theory and practice of trade terminology. Terminological theoretical frame is used in this paper.

Findings: The Incoterms were based in the first phase on historical principle, in the second phase on logical principle, in the third phase on functional principle. The creators of terminology must build a structure based on strict logic, eliminating the historical perspective, not making a difference between the original old and the artificially created new ones. The users preferred the old ones, building a structure using them to create a terminological structure. The ICC for a long time intended to force its own system in prescriptive method, but from the 2010 edition, it has concluded a compromise accepting the logic of everyday usage based on tradition in the 2020 edition.

Practical Implications: The paper gives a short overview of the rules of international trade from a terminological point of view.

Originality/Value: The changes of Incoterms have been investigated from legal, risk management, and logistical points of view but there is still now a gap in the research of Incoterms concerning the terminological perspective. Terminological analysis with its new instruments and view can reveal the principles of building the terminology, can mirror the changes of the power shifting.
\end{abstract}

Keywords: ICC, trade terminology, INCOTERMS, terminological standardization, terminological harmonization

JEL codes: F4, F19, N70

Research Type: Research paper.

${ }^{1}$ Ph.D. Eötvös Loránd University, Hungary vladar.zsuzsa@btk.elte.hu.

${ }^{2}$ Ph.D., Széchenyi István University, Hungary, laszlo.vasa@ifat.hu

${ }^{3}$ Ph.D., Szent István University, Hungary, callidusbt@gmail.com 


\section{Introduction}

The rules of International Commercial Terms (Incoterms) define the international sales contract's important elements, the so-called parity. The parity means the place where the cost and risks are handed over from the seller to the buyer. The purpose of the International Chamber of Commerce (ICC) issuing the Incoterms is to deliver a set of international regulations to explain the most common trade terms in international trade and sale contracts. Trade terms indicate the division of tasks, costs, and risks in the delivery of goods from the seller to the buyer. The ICC says that therefore using Incoterms, the uncertainties of different interpretations of these terms in different countries can be decreased.

The terms of Incoterms will be time to time redefined to adapt to the changing world. The terminology has been changing together with the changing way of thinking of world business. The first work published by the ICC on international trade terms was issued in 1923, with the first edition known as Incoterms published in 1936. The Incoterms rules were amended in 1953, 1967, 1976, 1980, 1990, and 2000, with the eighth version - Incoterms 2010 - published on January 1, 2011. The latest revision of Incoterms was published at the end of 2019 and is called Incoterms 2020.

The changes of Incoterms have been investigated from legal, risk management, and logistical points of view (Constantinovits and Sipos, 2016; Neszmélyi, 2019; Akbar et al., 2020) but there is still now a gap in the research of Incoterms concerning the terminological perspective. Terminological analysis with its new instruments and view can reveal the principles of building the terminology, can mirror the changes of the power shifting.

In this paper, we would like to get the answers to the following questions:

- What are the principles of the terminological system of Incoterms editions following each other?

- What is the difference between the logic of the creators of terminology and its users?

- How does change the relationship of users and ICC in the mirror of terminological changes?

\section{Theoretical Background}

As we apply terminological methods for getting the right answers, it is vital to give a short overview of the terminological theoretical frame used in the paper. The most important approaches and problems are the followings in the terminology.

\subsection{Standardization}

First, standardization was almost the exclusive aim of the terminology (Temmermann, 2000). This terminological approach was originated from the 
technical standardizations of industrial products. The first scholar was Eugene Wüster, engineer, who founded the so-called Wiener School of terminological research direction. This approach's linguistic background was based on the Saussurian structuralist semantics (Temmermann, 2000; Cabré, 1999).

The terminological standardization aimed to create an objective and closed structure of terms independent from users and situations, where formal definitions should define the terms. The term as a linguistic sign consists of sound and concept related to each other (onomasiological perspective). The Vienna School of Terminology's conceptual approach boils down to reducing conceptualization to a mental activity that can happen outside language. To achieve the univocity ideal, i.e., one unique term for each concept, Vienna school adherents need to believe that ideally, a term should be assigned to a concept.

The Technical Committee 37 of the ISO for language and terminology deals with the standardization of descriptions, resources, technologies, and services related to terminology, translation, interpreting, and other language-based activities in the multilingual information society (ISO, 2020).

According to this, the terms are defined exactly and straight, separated from each other. They prefer the intentional (Aristotelian) definitions; that is, we state a genus proximum and within the so-called differentia specific, which separates the concept from the other concepts within the category. The concepts are in a logical relationship with each other, building a hierarchical structure.

The meaning of the term equals the concept itself, independent of the users and the use circumstances. The conceptual structure has been created outside language and determines the terminology. There is one unique term for each concept, so there are no synonyms and polysemes. There is no room for misunderstandings because the defined and organized concepts remain the same, and only their names vary by language; that is why the translation is a straightforward task. The morphological structure of the terms (prefixes, compositions) reflects the concept's place in the conceptual hierarchy. This system has a prescriptive attitude. Generally, there is a central organization, which creates and develops the terminology.

\subsection{Socio-cognitive Approach}

In the former described approach, the standardization is high challenged by the practice. It is not possible to define the concepts outside language, as the human language creates categories by the words themselves, and every language creates its own categories, which naturally differ from each other. "Meanings are often quite vague and that many categories seem to be mentally represented in terms of prototypes rather than assets of critical features" (Weissenhofer, 1995, 193-194). The terminological structure is logically based, but using the terms in everyday business 
life, the terms and the metonymical relations between terms are also important for the users.

The professional knowledge covered by terms has been changing from time to time, and that is why the definitions which fixed the meanings became outdated and incorrect. The specialized terms are mostly metaphors, originating from common words or other terminology and their former meanings. Historically the terminologies were created spontaneously, which means there is always a period of time when there is no standardization. Even if it has happened to standardization, there is no guarantee that the discourse community will use it. In the above-mentioned theoretical problems, we discuss the terminology of INCOTERMS (International Commercial Terms) changing in time.

\subsection{International Trade Terminology}

International trade terminology is a special field of the economic language. It has been ruled for eighty years by the International Chamber of Commerce (ICC). The Incoterms is a set of standard trading terms defined by the ICC, which defines the division of costs and risks of delivering goods between the buyer and the seller according to the sales contract. "Since ICC first codified a set of standard trading terms as the Incoterms rules in 1936, this globally accepted contractual standard has been updated periodically to reflect the evolution of international trade." (INCOTERMS 2020). The fundamental weakness of terminology is that the terms need to meet with two opposite requirements: they need to be fixed, but they need to remain flexible in order to cope with technological and other changes (Vasa, 2010; Ercsey-Ravasz et al., 2012; Vladár, 2013; Dziubanovska, 2019; Vajda, 2020). Theoretical research focusing on regional trade systems are fundamental in this regard (Jámbor et al., 2020)

\section{Research Methodology}

The paper applies corpus analysis research with the qualitative philological method, identifying and evaluating the morphological structure changes. Qualitative corpus analysis is a methodology for conducting comprehensive examinations of linguistic phenomena, as grounded in the context of authentic, communicative situations that are digitally collected as language corpora and are available for access, retrieval, and analysis online. Qualitative corpus analysis is often used as the methodological basis for investigations "adopt an investigative, inductive approach to the o empiricallybased study of how the meanings and functions of linguistic forms found in the corpus" (Hasko, 2020). In our research, we used the following materials for our purposes, highlighting ICC rules for trade terms:

a) the ordering of the terms Incoterms 1980, 1990, 200, 2010, and 2020 editions;

b) notes and metatextual reflections in the introductory parts of Incoterms.

\section{Results}


We can distinguish three major phases in the development of Incoterms terminology, based on three logical backgrounds in creating the terminology.

\subsection{First Phase: The Chronological Principle}

Historically the everyday usage and practice created the trading customs concerning the costs, risks, and delivery. The first such custom was the so-called FOB (Free on Board), which means that the risk of loss or damage to the goods transfers from seller to buyer when the goods are on the vessel's board in the port of shipment. Moreover, the buyer bears all costs and risks from that moment. From this FOB parity derived the next parity named CIF (Cost, Insurance, and Freight), where the seller delivers the goods to the port of destination and bears all transport costs till that, but the transfer of the risk when the goods are on the board of the vessel in the port of shipment, that is at the same delivery point as in the case of FOB. These two terms were originally the basic terms of the sea trade, and all the others were originated from them. The name of the customs was English, and they have got a three-letter abbreviation. Without having exact definitions, their meaning has been varied port by port.

The growing world trade made it urgent to eliminate the uncertainties caused by the different usage of customs. That is why standardization was among the most important tasks of the ICC in 1936. The ICC gathered, defined, and named the most used trade customs, which we consider from these rules. The ICC worked chronologically, i. e., ordered the rules according to the date of their introduction. The last such ordering of rules was the version of INCOTERMS 1980.

Table 1. Chronologically Ordered Terms

Name of the rule

EXW Ex works

FOR/FOT Free on Rail/Free on Truck

FAS Free alongside ship

FOB Free on board

C\&F Cost and freight

CIF Cost, insurance and freight

EXS Ex ship

EXQ Ex quay

DAF Delivered at frontier

DDP Delivered duty paid

FOA Free on airport

FRC Free carrier

DCP Delivered carriage paid to

CIP Carriage and insurance paid to

entered into force
1953
1953
1953
1953
1953
1953
1953
1953
1967
1967
1976
1980
1980
1980

entered into force

1953

1953

1953

1953

1953

1967

1976

1980

1980

Source: INCOTERMS, 1980. 
We can see that the rules of 1980 follow each other according to the year of their codification, coping with the technical development (e.g., delivery by airplane). Worth noticing that this version has been introduced three new multimodal rules. They were intended to use for the so-called combined, multimodal, any mode of transport, which might be used for any use of transport even where more than one mode of transport was employed. (These were the FRC, DCP, CIP rules.) We can state that the beginning of worldwide containerization meant the beginning of the globalization of the 1980s, and the ICC enrichment of rules was the respective answer to that. The modern terms of multimodal delivery rules as being umbrella terms have been given the potential opportunity for substitution of the terms of traditional delivery rules.

\subsection{The Second Phase: The Strict Logical Principle}

In the 1980thies started the innovation of the Internet, making possible real-time international business transactions. The rush logistic supply chain management became a key element of the worldwide competitiveness using the so-called multimodal Incoterms parity made the business transactions easier, in a simpler way, and faster. That is why the next edition of Incoterms in 1990 has mirrored this global change and globalization. The ICC has changed the principle of the ordering of terms. Instead of the formal chronological system, the ICC introduced in 1990 a new system based on a logical approach. It was a new standardization of the terms, and it was two-sided: a) conceptual b) terminological. Building a conceptual system requested two steps: clarifying the conceptual hierarchy and assigning a term to each concept.

The first step was to integrate the traditional delivery modes (rail, truck, and airplane) into the so-called multimodal terms. For example, the FOA, FOR, FOT were canceled and replaced by the new parity FCA which was the renamed version of the FRC. The second step was making 4 conceptual groups according to the seller's obligations concerning the main carriage payment.

Table 2. Standardization of the concepts in INCOTERMS (1990): Integration of the concepts

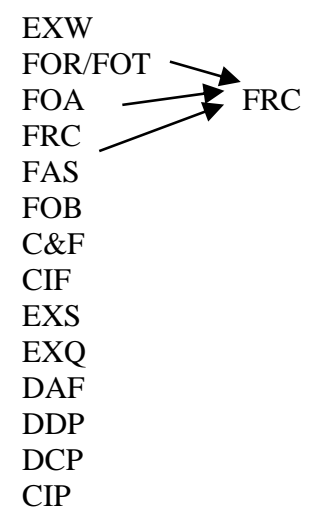

Source: Own creation. 
Table 3. Standardization of the Concepts in INCOTERMS (1990): Making 4 conceptual groups

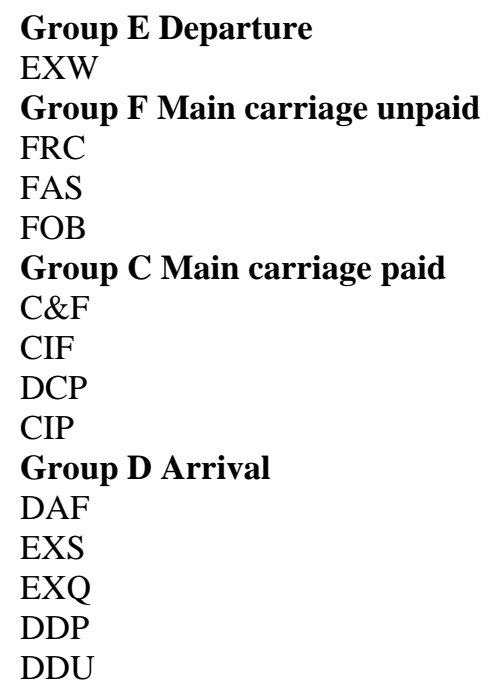

Source: Own creation.

The process went on with terminological standardization. The ICC renamed the terms (if needed) to formulate a homogeneous three-letter abbreviation of terms giving the same initial letter for the same group members. The first group consisted only of one member with $\mathrm{E}$ letter; the second was beginning with $\mathrm{F}$, the third with $\mathrm{C}$, the fourth with $\mathrm{D}$. The renaming was signed in the table below.

Table 4. Standardization of the terms in INCOTERMS (1990): Renaming the groups Group E

EXW

Group F

FRC (Free Carrier) $\longrightarrow$ FCA

FAS

FOB

Group C

C\&F (Cost \& Freight) $\longrightarrow$ CFR

CIF

DCP (Carriage freight paid to) $\longrightarrow$ CPT (Carriage paid to)

CIP

Group D

DAF

EXS (Ex Ship) $\longrightarrow$ DES (Delivered Ex Ship)
EXQ (Ex Quay) $\longrightarrow \quad$ DEQ (Delivered Ex Quay)

DDU (Delivered Duty Unpaid)

DDP (Delivered Duty Paid)

Source: Own creation.

The integration of concepts is clearly visible according to the table made by ICC 
referring to the mode of transport and the appropriate INCOTERMS (1990).

Table 4. Terminologically standardized list of terms

EXW

FCA

FAS

FOB

CFR

CIF

CPT

CIP

DAF

DES

DEQ

DDU

DDP

Source: Incoterms, 1990.

\subsection{The Third Phase: Clash between Standardization and Usage - Place of Sea Customs in the Terminological Structure}

Despite the standardization has remained three independent sea terms have got their multimodal equivalent terms artificially made by the ICC: FCA, CPT, CIP, which could serve as an umbrella term. In other words, we can see splitting the terms one group for multimodal, any mode of transport and other group able to use only for sea and waterway transport.

Table 5. Two groups of terms divided into sea and inland waterway and any mode ( $i$. e. non-waterway) terms Any mode of transport (including multimodal)

EXW

FCA (Air transport, Rail transport)

CPT

CIP

DAF

DDU

DDP

Sea and inland waterway transport

FAS

FOB

CFR

CIF

DES

Source: Incoterms, 1990.

DEQ

The ICC intended to eliminate the old sea terms by introducing the new multimodal umbrella terms. The metatextual reflections are demonstrate in Incoterms 1990: "It is expected that this term [FCA] will also be used for maritime transport in all cases where the cargo is not handed to the ship in the traditional method over the ship's rail. 
The traditional FOB-term is inappropriate where the seller is called upon to hand over the goods to a cargo terminal before the ships arrive..." (INCOTERMS, 1990, 6). The elimination of the sea terms seemed to be a logical step according to the terminological structure. Moreover, the ship's rail as a delivery point caused many business disputes. In 1990 the ICC did not delete the old sea terms because of the business community's will. This status quo was believed temporally, hoping to delete them in the next issue of INCOTERMS. However, it was not the case.

Incoterms 2000 has introduced only minimal changes. The waterway transport terms have not been eliminated from the system. The FOB and the CIF have remained the most used terms. "The delivery point under FOB ... has been left unchanged in INCOTERM 2000, despite a considerable debate. Although the notion under FOB to deliver the goods » across the ship's rail « nowadays may seem inappropriate in many cases, it is nevertheless understood by merchants and ... It was felt that a change of the FOB-point would create unnecessary confusion..." (INCOTERMS, 2000, 13).

The FOB term not only survived, but its usage has been broadened. It was used for not only sea delivery, but it was marked for delivery point of any other mode of transport.

\section{The Functional Principle}

The practice has proved that the business community is unwilling to accept the hierarchical, terminological structure based on pure logic. For the business community's practice, the sea terms have remained the main and the most important element of the structure, as is the traditional and basic point of international trade. The ICC from the beginning has dealt with the terminology with the purpose of institutional standardization, with respect only to the logical order. However, in the last ten years, a change has happened. The ICC has decided to adapt to the practice. Parallelly it has been a change in the principles of terminology as well. Besides, the structural point of view also spread the element of the functional approach.

The introduction of the multimodal terms in 1980 created the opportunity for replacing the sea terms with multimodal terms, but users insisted on sea terms. Moreover, the sea terms caused many problems because of the hardly understandable definition of delivery point "handling over the ship's rail." The ICC made a compromise in 2010 and 2020: keeping the sea terms but eliminating the delivery point concept. "The Incoterms $\mathbb{C}$ rules are presented in two distinct classes. rules for any mode or modes of transport and rules for sea and inland waterway transport.... All mention of the ship rail as the point of delivery has been omitted in preference for the goods being delivered when they are "on board" the vessel. This more closely reflects modern commercial reality and avoids the rather dated image of the risk swinging to and from across an imaginary perpendicular line" (INCOTERMS, 2010, 5). 
The INCOTERMS 2010 reduced the number of used terms, and the terminology also simplified, dividing the terms into two groups: sea and multimodal terms. The hidden split in the system has become explicit. As was mentioned before, it could have been foreseen in the 1990 and 2020 editions.

Table 6. Two groups of terms divided into sea and inland waterway and any mode (i. e. non-waterway) terms

Any mode of transport (including multimodal)

EXW
FCA
CPT
CIP
DAT
DAP
DDP

Sea and inland waterway transport

FAS

FOB

CFR

Source: Incoterms, 2010.

CIF

At the same time, despite the name of INCOTERMS, which is the abbreviation of International Commercial Terms intending to use it for only international trade, but in this issue, the ICC allowed to use it for domestic trade as well. "Incoterms rules have traditionally been used in international sale contracts ... The subtitle of the Incoterms (C) 2010rules formally recognizes that they are available for application to both international and domestic sale contracts. (INCOTERMS, 2010, 124).

Two developments persuaded the ICC. Firstly, the business community's practice: the traders commonly used the INCOTERMS for purely domestic contracts. Secondly, the willingness of the USA to unify the regulation of the business. Before 2010 the USA has used special customs and terms for domestic trade, which have the same name as in the INCOTERMS, but with a different meaning. Due to globalization, international trade's role increased for the USA, and two parallel living terms became disturbing. Otherwise, we should mention that the domestic trade terms in the USA were defined in the USA trade act. The ICC and the USA's business entity have made a logical decision to use the INCOTERMS 2010 for domestic use and international use.

\section{Conclusions}

The ICC is to promote international trade, responsible business conduct, and give a global approach to regulation and setting standards. Also, providing dispute resolution services. To achieve the above-mentioned goals, the ICC has used different means in different periods of time. In the first phase till 1980, the approach was defining and chronologically ordering the terms. 
In the second phase, the ICC wanted to improve the standardization using terminological ordering to eliminate misunderstandings and make unified and standard international trade. This remained only a wish because the business community considered the terminology, not from the hierarchical logic perspective but focusing on traditional sea customs as nodes of a terminological network.

The third phase, the global way of thinking together with the trend of simplification, remain unchanged and continued in the terminology, at the same time was characterized by the functional changes, that were the consideration of viewpoint of the business community concerning the terminological structure, highly simplification, and giving up the identity of the international business character to get a broadened use of terms (see INCOTERMS 2010 and 2020).

According to the research questions, we can state:

- We can conclude that the Incoterms were based in the first phase on historical principle, in the second phase on logical principle, in the third phase on functional principle.

- The creators of terminology must build a structure based on strict logic, eliminating the historical perspective, not making a difference between the original old and the artificially created new ones. The users preferred the old ones, building a structure using them to create a terminological structure.

- The ICC for a long time intended to force its own system in prescriptive method, but from the 2010 edition, it has concluded a compromise accepting the logic of everyday usage based on tradition in the 2020 edition.

\section{References:}

Akbar, U., Kumar, A., Khan, H., Asif Khan, M., Parvaiz, K., Oláh, J. 2020. Trade-Offs in Competitive Transport Operations. Economies, 8(3), 1-19.

Cabré, M.T. 1999. Terminology (ed. Juan Sager, transl. Janet Decesaris). John Benjamins, Amsterdam/Philadelphia.

Constantinovits, M., Vladár, Z. 2013. Cultural roots of foreign trade terminology. Jẹzyk, Komunikacja, Informacja, 8, 50-57.

Constantinovits, M., Sipos, Z. 2016. Nemzetközi üzleti technikák. Akadémiai Kiadó, Budapest.

Dzialo, J., Gawronska-Nowak, B., Jura, J. 2017. Social Debate on Free Trade Agreements: Illusions Versus Reality. Economics and Sociology, 10(3), 116-135.

Dziubanovska, N. 2019. Multifactor models for studying the EU countries' international trade. Economic Annals-XXI: Volume 175 (1-2), 29-34.

Ercsey-Ravasz, M., Toroczkai, Z., Lakner, Z., Baranyi, J. 2012. Complexity of the International Agro-Food Trade Network and Its Impact on Food Safety. Plos One, 7(5). https://doi.org/10.1371\%2Fjournal.pone.0037810.

Hasko, V. 2020. Qualitative Corpus Analysis. The Encyclopedia of Applied Linguistics. Wiley Online Library 10.1002/9781405198431.wbeal0974.pub2.

INCOTERMS. 1990. The official text of Incoterms 1990 developed under the auspices of 
the International Chamber of Commerce. ICC. ICC Publication No. 460.

INCOTERMS. 2000. ICC Official Rules for the Interpretation of Trade Terms. International Chamber of Commerce. ICC Publication No. 560.

INCOTERMS. 2010. ICC Rules for the Use of Domestic and International Trade Terms. Entry into Force: 1 January 2011. International Chamber of Commerce. ICC Publication No. 715E.

INCOTERMS. 2020. ICC Rules for the Use of Domestic and International Trade Terms. ICC Publication No. 723E.

Jámbor, A., Gál, P., Török, Á. 2020. Determinants of regional trade agreements: Global evidence based on gravity models. Journal of International Studies, 13(1), 44-57.

Moroz, S., Nagyova, L., Bilan, Y., Horska, E., Polakova, Z. 2017. The current state and prospects of trade relations between Ukraine and the European Union: the Visegrad vector. Economic Annals-Xxi, 163(1-2), 14-21.

Neszmélyi, G. 2019. Economic and social factors in Taiwan's competitiveness with special focus on the Taiwan-EU trade relations. Studia Mundi - Economica, 6 (1)165179.

Temmermann, R. 2000. Towards New Ways of Terminology Description: The Sociocognitive-approach. John Benjamins Amsterdam/Philadelphia.

Vajda, A., Magda, R. 2020. Foreign Trade in the View of Competitiveness in the EU. Polgári Szemle: Gazdasági és Társadalmi Folyóirat, 16(4-6), 149-158.

Vasa, L., Mendelényi, D. 2010. The Dominant Issues in Free Trade and in International Economic System. In: Magda, S., Dinya, L. (eds). 12th International Scientific Days. Gyöngyös, Hungary, 86-92.

Weissenhofer, P. 1995. Conceptology in Terminology Theory, Semantics and Word Formation. Vienna: Termnet. 